\title{
HUBUNGAN PERAWATAN KELUARGA DENGAN PERSONAL HYGIENE PADA LANSIA DI DUSUN ASEM NUNGGAL DESA KALIANGET BARAT KECAMATAN KALIANGET
}

Mujib Hannan, Program Studi IImu Keperawatan UNIJA Sumenep

e-mail: Mujib@wiraraja.ac.id

Dian Ika Puspitasari, Program Studi IImu Keperawatan UNIJA Sumenep

e-mail: dianika.uwr@gmail.com

\section{ABSTRACT}

Family care affects personal hygiene on the elderly this indicates that care family is the family indicator in performing the function of health while the personal hygiene is a parameter that used to improve the care of the family. The aims of this research are to know relationship between the treatment of families with personal hygiene on the elderly in Dusun Asem Nunggal Desa Kalianget Barat Kecamatan Kalianget.

This research is quantitative with cross sectional approach. Population are all elderly in Dusun Asem Nunggal Desa Kalianget Barat Kecamatan Kalianget are 56 people. The number of samples are 49 people with simple random sampling. Data analysis using the Spearman Rho to test $(\alpha=0.05)$. Data collection using observation and family care questionnaires and personal hygiene.

The results of research on family care shows most $(57,1 \%)$ do good family care. While the results of research about personal hygiene showed the majority of respondents (61,2\%) do personal hygiene well. The results of the test using the corelation of spearman rho indicates $p$ value $=0.000$ which means there is a significant relationship between family care with personal hygiene on the elderly.

Families can improve the care of the family and understand more about health problems in the elderly. The elderly must maintain personal hygiene on him. The better care the family performed on the elderly then personal hygiene on the elderly is also getting better.

Keywords: Maintenance(Care), Personal Hygiene, Elderly

\section{PENDAHULUAN}

Pemeliharaan kebutuhan fisik diperlukan untuk rasa nyaman dan aman dari perasaan sehat seorang individu. Secara normal seseorang yang sehat mampu untuk memenuhi kebutuhan akan kebersihan dirinya sendiri (Clevo, 2013). Usaha pemeliharaan kebersihan diri seperti kebersihan, mata, telinga, gigi, dan lainnya. Usaha pemeliharaan kebersihan diri, keluarga memiliki tanggung jawab dalam melakukan perawatan kebersihan diri terhadap anggota keluarga yang lain.

Salah satu budaya masyarakat Indonesia terkait lansia yaitu memilih untuk merawat lansia dikeluarga sendiri dengan tidak melibatkan panti. Peran keluarga terhadap kehidupan lansia berkisar $80 \%$ dimana keluarga selalu memberikan support pada lansia. Terdapat $75 \%$ lansia yang berusia lebih dari 65 tahun dirawat oleh anggota keluarganya sendiri, yang seperempatnya merupakan pasangan hidup serta lebih dari sepertiga yang dirawat oleh pasangannya (Fatimah, 2010).

Keluarga dalam hal ini sangat diperlukan yaitu dalam menjaga kesehatan keluarganya terutama dalam memenuhi kebutuhan personal hygiene yang kurang dikarenakan keluarga merupakan motivator untuk kesehatan dan penentu untuk masalah kesehatan keluarganya. Salah satu faktor yang berpengaruh pada kesehatan dan psikis lansia. Permasalahan pada lansia dapat menyebabkan beberapa masalah fisik, psikologis ataupun sosial ekonomi. Bertambahnya umur menyebabkan kemunduran terutama kemampuan fisik, yang dapat menyebabkan berkurangnya peran sosialnya sehingga menyebabkan masalah dalam memenuhi kebutuhan kebersihan diri yang bisa menambah ketergantungan pada orang lain (Nugroho dalam Widyaningsih, 2013).

Badan Pusat Statistik (BPS, 2009) memprediksi pada abad 21 negara Indonesia akan menjadi abad lansia karena pertumbuhan penduduk lansia yang akan cepat daripada negara lain. WHO memprediksi tahun 2025 Indonesia akan terjadi penambahan lansia mencapai 41,4\%, dan merupakan tertinggi didunia. Populasi lansia di Indonesia pada saat ini mencapai rata-rata $7,5 \%$ total jumlah penduduk yang 20 tahun ke depan diprediksi akan melebihi balita (Reny, 2014). 
Pertambahan jumlah lansia rata-rata 450.000 orang tiap tahunnya padahal jumlah lansia di Jawa Timur mencapai 2.971.004 jiwa atau 9,36\% (Dinsos, 2013).

Berdasarkan data dari Dinas Kesehatan Sumenep tahun 2014, jumlah warga lanjut usia di Kabupaten Sumenep sebanyak 206.842 jiwa. Data di Puskesmas Kalianget yang menaungi 7 daerah posyandu lansia, prevalensi pralansia tahun 2014 sebanyak 9.400 jiwa, dan lansia sebanyak 3.799 jiwa. Data lansia di Desa Kalianget Barat sebanyak 336 jiwa, sedangkan jumlah lansia di Dusun Asem Nunggal sebanyak 56 jiwa. Perubahan fisik yang dialami oleh lansia menyebabkan kemampuan untuk menjaga kebersihan diri kurang baik dan menyebabkan lansia membutuhkan bantuan dari keluarga untuk melakukan perawatan kebersihan diri. Berdasarkan pengambilan data awal pada tanggal 4 Januari 2016 yang dilakukan dengan wawancara pada lansia di Dusun Asem Nunggal Desa Kalianget Barat Kecamatan Kalianget yang didampingi keluarganya dari 10 lansia, orang giginya sudah tidak lengkap sehingga tidak usah membersihkan mulut, dan mereka tidak tahu cara merawat mulut yang tidak adanya gigi. Sebagian lansia kukunya tampak panjang dan kotor, mereka peduli dengan kebersihan kuku, yang merupakann sumber penyakit.

Kebersihan diri adalah awal dalam mencapai kesehatan. Tubuh yang bersih dapat mencegah berbagai macam penyakit. Beberapa dampak karena tidak menjaga kebersihan badan yaitu: gatal-gatal dan penyakit kulit. Rambut akan berketombe/kutu, kuku yang kotor merupakan tempat kuman penyebab penyakit pencernaan, gigi dan mulut yang kotor akan mengakibatkan karies gigi, bau mulut dan lainnya. Hal-hal yang bisa dilakukan keluarga dalam memenuhi kebutuhan personal hygiene lansia adalah keluarga berperan membantu, merawat dan memberi motivasi kepada para lansia agar lansia yang tidak mampu melakukan personal hygiene mampu melakukannya.

Cara lain yang bisa dilakukan keluarga dalam merawat lansia untuk memenuhi personal hygiene adalah membantu menyiapkan air untuk mandi, membantu sabun bagi lansia yang tidak mampu melakukannya, membantu dalam mencuci rambut, membantu ganti pakaian pada lansia yang sudah tidak bisa melakukan personal hygiene sendiri, keluarga sebagai orang terdekat dalam merawat atau memberikan perawatan diri pada lansia tersebut agar lansia terhindar dari suatu penyakit. Dengan demikian peneliti tertarik untuk meneliti "Hubungan Perawatan Keluarga dengan Kebutuhan Personal hygiene pada Lansia di Dusun Asem Nunggal Desa Kalianget Barat Kecamatan Kalianget".

\section{BAHAN DAN CARA PENELITIAN}

Penelitian ini merupakan jenis analitik cross sectional. Tujuan penelitian yaitu mengetahui hubungan perawatan keluarga dengan personal hygiene pada lansia di Dusun Asem Nunggal Desa Kalianget Barat Kecamatan Kalianget. Populasi dalam penelitian ini yaitu lansia yang berumur lebih dari 60 tahun dan tinggal bersama keluarganya di Dusun Asem Nunggal Desa Kalianget Barat Kecamatan Kalianget yang berjumlah 56 orang. Sampel adalah sebagian lansia yang berumur $>60$ tahun dan tinggal bersama keluarganya di Dusun Asem Nunggal Desa Kalianget Barat Kecamatan Kalianget sebanyak 49 orang. Pengambilan sampel menggunakan Simple Random Sampling, kriteria Inklusi sampel yaitu: Lansia dengan usia diatas 60 tahun, Lansia yang tinggal bersama dengan keluarganya, Lansia yang sehat, pendengaran baik, Tidak menderita demensia, bersedia untuk menjadi responden, Keluarga merawat lansia, Lansia maupun keluarga bisa membaca, menulis. Kriteria eksklusi yaitu: tidak bersedia menjadi responden, tidak memiliki lansia, tidak sampai umur 60 tahun, tidak tinggal bersama keluarga. Instrumen dalam penelitian ini adalah kuesioner digunakan untuk wawancara tentang personal hygiene pada lansia dan variable perawatan keluarga menggunakan kuesioner yang dimodifikasi dari penelitian Rosy (2014).

\section{HASIL PENELITIAN}

\section{Data Umum}

\subsection{Karakteristik Lansia menurut Usia}

Tabel 1.1 Karakteristik lansia menurut usia di Dusun Asem Nunggal Desa Kalianget Barat Kecamatan Kalianget.

\begin{tabular}{cccc}
\hline No & Usia & Jumlah & Prosentase \\
\hline 1 & $60-70$ th & 47 & 95.9 \\
2 & $75-90$ th & 2 & 4.1 \\
3 & $>90$ th & 0 & 0 \\
\hline & Total & 49 & 100 \\
\hline
\end{tabular}

Tabel 1.1 menunjukkan bahwa hampir seluruhnya berusia yaitu 60-70 tahun (elderly) yaitu sebanyak 47 orang $(95,9 \%)$. 
1.2 Karakteristik Lansia menurut Jenis Kelamin

Tabel 1.2 Karakteristik lansia menurut jenis kelamin di Dusun Asem Nunggal Desa Kalianget Barat Kecamatan Kalianget.

\begin{tabular}{|c|c|c|c|}
\hline No & Jenis kelamin & Jumlah & Prosentase \\
\hline 1 & Laki-laki & 9 & 18.4 \\
\hline \multirow[t]{2}{*}{2} & Perempuan & 40 & 81.6 \\
\hline & Total & 49 & 100 \\
\hline
\end{tabular}

\subsection{Karakteristik Keluarga Lansia Menurut Pendidikan}

Tabel 1.3 Karakteristik keluarga lansia menurut pendidikan di Dusun Asem Nunggal Desa Kalianget Barat.

\begin{tabular}{cccc}
\hline No & Pendidikan & Jumlah & Prosentase \\
\hline 1 & Tidak tamat SD & 1 & 2 \\
2 & SD & 4 & 8.2 \\
3 & SMP & 12 & 24.5 \\
4 & SMA & 26 & 53.1 \\
5 & Perguruan tinggi & 6 & 12.2 \\
\hline & Total & 49 & 100 \\
\hline
\end{tabular}

Tabel 1.3 menunjukkan sebagian besar keluarga lansia berpendidikan SMA yaitu sebanyak 26 orang $(53,1 \%)$

\subsection{Karakteristik keluarga menurut pekerjaan}

Tabel 1.4 Karakteristik responden keluarga menurut pekerjaan di Dusun Asem Nunggal Desa Kalianget Barat Kecamatan Kalianget

\begin{tabular}{|c|c|c|c|}
\hline No & Pekerjaan & Jumlah & Prosentase \\
\hline 1 & Swasta & 7 & 14.3 \\
\hline 2 & $\mathrm{IRT}$ & 38 & 77.5 \\
\hline 3 & PNS & 4 & 8.2 \\
\hline & Total & 49 & 100 \\
\hline
\end{tabular}
seluruhnya keluarga lansia bekerja sebagai ibu rumah tangga yaitu sebanyak 38 orang $(77,5$ $\%)$

\section{Data Khusus}

\subsection{Perawatan Keluarga}

Tabel 2.1 Distribusi responden menurut perawatan keluarga di Dusun Asem Nunggal Desa Kalianget Barat Kecamatan Kalianget.

\begin{tabular}{cccc} 
No & Kategori & Jumlah & Prosentase \\
\hline 1 & Baik & 28 & 57.2 \\
2 & Cukup & 15 & 30.6 \\
3 & Kurang & 6 & 12.2 \\
\hline & Total & 49 & 100 \\
\hline
\end{tabular}

Tabel 2.1 menunjukkan bahwa sebagian besar keluarga melakukan perawatan keluarga dengan baik yaitu sebanyak 28 orang $(57,2 \%)$

\subsection{Personal hygiene pada lansia}

Tabel 2.2 Distribusi responden menurut personal hygiene pada lansia di Dusun Asem Nunggal Desa Kalianget Barat Kecamatan Kalianget.

\begin{tabular}{cccc}
\hline No & Kategori & Jumlah & Prosentase \\
\hline 1 & Baik & 30 & 61.2 \\
2 & Cukup & 12 & 24.5 \\
3 & Kurang & 7 & 14.3 \\
\hline & Total & 49 & 100 \\
\hline
\end{tabular}

Tabel 2.2 menunjukkan bahwa sebagian besar responden melakukan personal hygiene dengan baik yaitu sebanyak 30 orang $(61,2 \%)$

\subsection{Hubungan Perawatan Keluarga Dengan Personal Hygiene Pada Lansia}

Tabel 2.3 Tabulasi silang antara perawatan keluarga dengan personal hygiene pada lansia di Dusun Asem Nunggal Desa Kalianget Barat Kecamatan Kalianget.

\begin{tabular}{cccccccccc}
\hline \multirow{2}{*}{ No } & Perawatan & \multicolumn{2}{c}{ Baik } & \multicolumn{2}{c}{ Cukup } & \multicolumn{2}{c}{ Kurang } & \multicolumn{3}{c}{ Total } \\
\cline { 2 - 10 } & keluarga & $\mathrm{F}$ & $\%$ & $\mathrm{~F}$ & $\%$ & $\mathrm{~F}$ & $\%$ & $\mathrm{~F}$ & $\%$ \\
\hline 1 & Baik & 19 & 67.9 & 6 & 214 & 3 & 10.7 & 28 & 100 \\
2 & Cukup & 7 & 46.7 & 5 & 333 & 3 & 20 & 15 & 100 \\
3 & Kurang & 4 & 66.6 & 1 & 167 & 1 & 16.7 & 6 & 100 \\
& Total & 30 & 61.2 & 12 & 245 & 7 & 14.3 & 49 & 100 \\
\hline
\end{tabular}

$P$ value: $0.000(<\alpha: 0.05)$ correlation coefficient : 0,685 
Tabel 2.3 menunjukkan pada perawatan keluarga baik yaitu sebanyak 28 orang dengan personal hygiene pada lansia baik yaitu sebanyak 19 orang $(67,9 \%)$, personal hygiene pada lansia cukup yaitu sebanyak 6 orang $(21,4 \%)$, sedangkan personal hygiene pada lansia kurang yaitu sebanyak 3 orang $(10,7 \%)$. Pada perawatan keluarga cukup yaitu sebanyak 15 orang dengan personal hygiene pada lansia baik yaitu sebanyak 7 orang $(46,7 \%)$, personal hygiene pada lansia cukup yaitu sebanyak 5 orang $(33,3 \%)$, sedangkan personal hygiene pada lansia kurang yaitu sebanyak 3 orang (20\%).

Pada perawatan keluarga kurang yaitu sebanyak 6 orang dengan personal hygiene pada lansia baik yaitu sebanyak 4 orang (66,6\%), personal hygiene pada lansia cukup yaitu sebanyak 1 orang (16,7\%), sedangkan personal hygiene pada lansia kurang yaitu sebanyak 1 orang $(16,7 \%)$. Hasil analisa data dengan uji statistik dengan uji Spearman's Rho didapatkan $p$ value $=0,000$ dengan nilai $\alpha$ : 0,05 dan koefisien korelasi 0,685 , jadi $p(0,000)$ $<\alpha(0,05)$ berarti ada hubungan perawatan keluarga dengan personal hygiene pada lansia di Dusun Asem Nunggal Desa Kalianget Barat Kecamatan Kalianget.

\section{PEMBAHASAN}

\section{Perawatan Keluarga}

Hasil penelitian menunjukkan sebagian besar $(57,2 \%)$ perawatan keluarga baik. Peneliti berasumsi bahwa perawatan keluarga baik disebabkan oleh kemauan dari pihak keluarga misalnya keluarga mengajarkan lansia untuk membersihkan gigi, mandi sehari 2 kali. Usia keluarga sebagian besar beusia 31-40 tahun yang merupakan kategori produktif (Hitchcock, Schubert et al, 2011). Populasi produktif dalam bertanggung jawab terhadap lansia yang harus mendapatkan perawatan disebabkan oleh keterbatasannya. Jenis kelamin keluarga terbesar yaitu perempuan. Menurut Meiner (2006) bahwa $75 \%$ yang memberikan layanan kesehatan lansia yaitu perempuan. Dalam penelitian ini jumlah keluarga yang berjenis kelamin perempuan yaitu sebesar $89,8 \%$.

Perempuan diharapkan bisa memberikan motivasi, perhatian serta perawatan lansia. Menurut Fingerman (2001) terdapat hubungan antara anak perempuan dan orang tua perempuan dan kedekatan emosional, maka diharapkan mampu melakukan perawatan keluarga pada lansia terutama dalam hal perawatan keluarga terhadap personal hygiene.
Pendidikan keluarga terbesar yaitu SMA sebesar 53,1\%. Pengetahuan keluarga mempengaruhi keterampilan serta pemahaman untuk pemberian perawatan anggota keluarganya. Pendidikan berhubungan dengan status kesehatan karena penting dalam meningkatkan pengetahuan dan perilaku (Notoadmojo, 2003). Bertambahnya pemahaman keluarga tentang kebersihan diri lansia akan dapat meningkatkan perawatan keluarga pada lansia. Hasil penelitian didapatkan pekerjaan keluarga terbanyak berada pada kategori ibu rumah tangga, swasta, PNS.

Keluarga dengan pekerjaan sebagai ibu rumah tangga sebesar $77,5 \%$. Berdasarkan analisis hasil dapat dinyatakan bahwa pekerjaan pada keluarga akan mempengaruhi keluarga dalam melakukan perawatan keluarga terhadap lansia seperti kebersihan diri pada lansia. Perawatan terhadap lansia dilakukan oleh anggota keluarga. Keluarga berperan penting dalam ketersediaan sumber penting untuk pelayanan kesehatan dirinya dan keluarga. Menrut Mainer (2006) masih banyak terdapat keluarga yang tidak mengantisipasi adanya kebutuhan dalam menyiapkan perawatan orang tuanya. Kadang keluarga kurang perhatian pada kebutuhan spesifik lansia dan perlakuan yang sama pada dibandingkan dengan anggota keluarga lainnya. Penyebab hal ini yaitu kurangnya informasi keluarga tentang permasalahan lansia terutama informasi tentang personal hygiene pada lansia.

\section{Personal Hygiene Pada Lansia}

Berdasarkan hasil penelitian menunjukkan bahwa sebagian besar $(61,2 \%)$ personal hygiene pada lansia baik. Umur harapan hidup perempuan lebih tinggi dibandingkan dengan laki-laki. Perempuan yaitu 66,7 tahun dan laki-laki yaitu 62,9 tahun (Depkes, 2014). Dalam penelitian ini jumlah penduduk lansia perempuan lebih banyak dibandingkan dengan laki-laki yaitu berjumlah berjumlah 40 responden. Pendidikan lansia terbesar yaitu tidak sekolah, SD dan SMP. Menurut Ramlah (2011) di Indonesia pendidikan lansia pada kategori rendah.

Pendidikan berpengaruh pada harapan kesehatan lansia dan berdampak pada perilaku untuk memenuhi kebutuhan kebersihan diri. Hasil analisa menunjukkan jika tingkat pendidikan berpengaruh pada perilaku untuk menerima informasi, pola pengetahuan dan perilaku lansia, utamanya dalam memelihara 
kebersihan diri. Jenis pekerjaan lansia yang terbesar adalah ibu rumah tangga, pensiunan, tidak bekerja dan swasta. Lansia dengan pekerjaan sebagai ibu rumah tangga sebesar $63,3 \%$. Hasil penelitian menunjukkan jika pekerjaan berpengaruh pada lansia dalam menjaga kebersihan diri.

Personal hygiene adalah perawatan diri sendiri sebagai upaya menjaga kesehatan fisik ataupun psikologis yang dipengaruhi oleh faktor-faktor yaitu: budaya, kondisi fisik, psikologis dan keuangan (Gateaway, 2013). Kemampuan lansia dalam melakukan pemenuhan perawatan diri sangat dipengaruhi oleh kemandirian lansia dalam melakukan aktivitas sehari-harinya. Lansia dengan personal hygiene yang baik lebih dapat diterima di masyarakat dibandingkan dengan lansia yang memiliki personal hygiene yang kurang baik. Lansia dengan personal hygiene yang baikpun menurunkan resiko untuk terjadi penyakit infeksi.

Kebutuhan akan personal hygiene harus menjadi prioritas utama bagi lansia, karena dengan personal hygiene yang baik maka lansia memiliki resiko yang rendah untuk mengalami penyakit infeksi(Gateaway, 2013). Upaya pemeliharaan personal hygiene seperti: kebersihan rambut, gigi, mulut dan lainnya. Dalam upaya untuk menjaga personal hygiene ini, pengetahuan keluarga tentang pentingnya personal hygienesangat diperlukan. Tindakan seseorang dapat dibentuk dengan pengetahuan atau kognitif, sehingga kognitif atau pengetahuanmerupakan domain yang sangat penting.

\section{Hubungan perawatan keluarga dengan personal hygiene pada lansia}

Berdasarkan hasil

penelitian

menunjukkan bahwa ada hubungan perawatan keluarga dengan personal hygiene pada lansia di Dusun Asem Nunggal Desa Kalianget Barat Kecamatan Kalianget. Peneliti berasumsi bahwa pada lansia dengan personal hygine secara baik dan perawatan keluarga dengan baik disebabkan kemauan dan kemampuan dari keluarga lansia dan lansia dalam melakukan kebersihan dirinya seperti mandi, menyisir rambut, memotong kuku lansia serta menyikat gigi lansia.

Keluarga yang membantu lansia dalam perawatan keluarga akan mempengaruhi personal hygiene misalnya lansia yang tidak mempunyai gigi harus tetep menyikat gigi selama 2 kali sehari dan lansia yang tidak mau memotong kuku selama 1 minggu sekali hal tersebut akan mempengaruhi personal hygiene pada lansia. Hal tersebut didukung penelitian Wahyuni (2012) yaitu terdapat hubungan dukungan keluarga dengan personal hygiene pada lansia. Penelitian lain juga dilakukan oleh Zamsari (2014) menyatakan terdapat hubungan peran keluarga dengan pemenuhan kebutuhan perawatan diri pada lanjut usia.

Hasil uji statistik menggunakan uji Spearman menghasilkan perawatan keluarga memiliki hubungan dengan personal hygiene pada lansia. Perawatan keluarga yang dilakukan kepada lansia sangat berpengaruh kepada personal hygiene pada lansia, kemampuan lansia dalam melakukan perwatan diri membutuhkan bantuan dari keluarga. Lansia harus didukung dalam pelaksanaan kegiatan personal hygiene dengan baik karena dapat menguntungkan, hemat biaya, tenaga, dan waktu untuk menunjang kesehatan dan kesejahteraan. Pengembangan personal hygiene serta perlindungan lingkungan merupakan perlindungan khusus yang bisa berpengaruh pada tingkat kesehatan (Dainur, 1995).

Hal-hal yang bisa dilakukan keluarga dalam memenuhi kebutuhan personal hygiene lansia adalah keluarga berperan membantu dan memberi motifasi kepada para lansia agar lansia yang tidak mampu melakukan personal hygiene mampu melakukannya. Dengan adanya motivasi dan bantuan dari keluarganya yaitu mengajak lansia untuk aktif dalam merawat dirinya. Manusia adalah makhluk sosial yang akan memungkinkan seseorang dalam berinteraksi, dengan orang lain. Personal hygiene berpengaruh terhadap kebiasaan keluarga dalam praktik higiene, contohnya saat mandi dan membersihkan mulut. lansia akan mengalami berbagai perubahan dalam melakukan praktik higiene yang disebabkan oleh perubahan kondisi fisik (Andarmoyo, 2012).

Ketika lansia memiliki personal hyigene yang kurang, lansia akan diasingkan dari lingkungan sekitar karena masyarakat akan menila lansia tidak memperdulikan tentang kebersihannya yang mana akan berpengaruh pada interaksi lansia dengan msayarakat serta keluarga. Cara lain yang bisa dilakukan keluarga dalam merawat lansia untuk memenuhi personal hygiene adalah membantu menyiapkan air untuk mandi, membantu menyiapkan sabun bagi lansia yang tidak mampu melakukannya, membantu dalam mencuci rambut, membantu ganti pakaian pada lansia yang sudah tidak bisa melakukan 
personal hygiene sendiri, keluarga sebagai orang terdekat dalam merawat atau memberikan perawatan diri pada lansia tersebut agar lansia terhindar dari suatu penyakit. Oleh karena itu, dapat disimpulkan bahwa perawatan keluarga mempunyai hubugan terhadap personal hygiene pada lansia sehingga terjadi peningkatan kesehatan pada lansia.

Keluarga lansia yang memiliki lansia harus lebih memperhatikan kebersihan lansia, karena ketika lansia bersih maka lansia akan terjadi peningkatan kesehatan pada lansia. Lebih banyak lansia yang masih melakukan pemenuhan personal hygiene dengan sendirinya. Lansia terkadang malu untuk meminta bantuannya kepada anaknya sendiri dikarenakan dia mersa mampu melakukan semuanya sendiri. Sebagai anak yang tinggal dengan orang tua yang dikategorikan sebagai lansia seharusnya anak harus memperhatikan tentang kesehatan orang tua mereka.

\section{KESIMPULAN DAN SARAN}

\section{Kesimpulan}

1. Sebagian besar keluarga melakukan perawatan keluarga terhadap lansia dengan baik.

2. Sebagian besar lansia melakukan personal hygiene dengan baik.

3. erdapat hubungan signifikan perawatan keluarga dengan personal hygiene lansia di Dusun Asem Nunggal Desa Kalianget Barat Kecamatan Kalianget.

\section{Saran}

1. Bagi Responden/Keluarga

Diharapkan responden dapat mempertahankan personal hygiene yang baik dan diharapkan pula untuk keluarga dapat meningkatkan perawatan keluarga kepada lansia, sehingga meningkat kualitas kesehatan lansia.

2. Bagi perawat

Adanya pengembangan kemampuan perawat komunitas dalam praktik keperawatan dalam melaksanakan personalhygiene pada lansia, sehingga tingkat penyebaran penyakit terhadap lansia bisa dicegah.

3. Bagi pendidikan keperawatan

Kepada pihak institusi pendidikan diharapkan dapat meningkatkan kemampuan mahasiswa dalam memberikan penyuluhan kesehatan tentang pentingnya perawatan keluarga dengan personal hygiene pada lansia serta memberikan mata kuliah tentang personal hygiene pada lansia, sehingga dalam praktik dilapangan mahasiswa dapat memberikan informasi yang baik untuk menambah pengetahuan untuk keluarga dan lansia.

4. Bagi Penelitian Selanjutnya

Penelitian selanjutnya diharapkan melakukan penelitian menggunakan variabel-variabel lainnya, seperti citra tubuh, kondisi fisik, persepsi terhadap perawatan dan dapat menambah jumlah sampel yang lebih luas agar dapat hasil yang lebih akurat.

\section{DAFTAR PUSTAKA}

Ambarwati, F. R. (2014). Konsep Kebutuhan Dasar Manusia. Yogyakarta: Parama IImu.

Andarmoyo. (2012). Konsep Dasar Keluarga. https://www.google.co.id/konsepdasarkeluarga.co.id tanggal 5 Januari 2016 jam 19.00 WIB.

Ananggadipa, S (2012). Studi Empiris Pada Penggunaan Aplikasi Pajak Integrasi Theory Of Planned Behavior and Technoligy Acceptance Model. Skripsi, Program Sarjana Fakultas Ekonomika dan Bisnis Universitas Dipenogoro. Semarang.

Aspiani, R. (2014). Buku Ajar Asuhan Keperawatan Gerontik, Aplikasi NANDA, NIC, dan NOC Jilid 1. Jakarta: Trans Info Media.

Azizah, et al, (2011). Keperawatan LanjutUsia. Edisi 1. Yogyakarta : Grahallmu.

Clevo, R. (2013). Buku Saku : Keterampilan Dasar Keperawatan. Yogyakarta : Nuha Medika.

Dainur (1995). Materi-Materi Pokok IImu Kesehatan Masyarakat. Jakarta : Widya Medika

Fatimah. (2010). Merawat Manusia lanjut Usia Suatu Pendekatan Proses Keperawatan Gerontik. Jakarta: Trans Info Media.

Ferry Efendi. (2009). Keperawatan Kesehatan Komunitas: Teori Dan Praktek Dalam Keperawatan. Jilid 1. Jakarta:Salemba Medika.

Fibriyanto, S (2013). Hubungan Personal Hygiene Keluarga Penderita Kusta dengan Upaya Pencegahan Penularan Penyakit Kusta di Wilayah Kerja UPT PUSKESMAS DUNGKEK Tahun 2013. Program Studi IImu Keperawatan. Universitas Wiraraja Sumenep.

Friedman, et al (2012). Buku ajar keperawatan keluarga : Riset, Teori dan Praktek. Jakarta:EGC. 
Handayani, Z. N. (2014). Hubungan Peran Keluargan Dengan Pemenuhan Kebutuhan Perawatan Diri Pada Lansia Di Dusun Jogonalan Lor Kasihan Bantul.Program Studi IImu Keperawatan. Sekolah Tinggi IImu Kesehatan 'Aisyiyah Yogyakarta.

Hidayat, A, (2009). Metode Penelitian Keperawatan dan Teknik Analisis Data. Jakarta: Salemba Medika.

Maryam, R. (2008). Mengenal Usia Lanjut \& Perawatannya. Jakarta : Salemba medika. Meiner \& Lueckenotte. (2006). Gerontologi Nursing Third Edition. Philadelphia: Mosby Company.

Mubarak, et.al. ( 2009 ). Ilmu Keperawatan Komunitas Konsep dan Aplikasi. Jakarta : Salemba Medika

Mubarak, et.al. (2012). IImu Keperawatan Komunitas 2; konsep dan aplikasi. Jakarta : Salemba Medika.

Moleong, L (2013). Metodologi Penelitian Kualitatif. Edisi Revisi, Cetakan ke-20, Bandung : PT. Remaja Rosdakarya Offset.

Nugroho, W (2008). Keperawatan Gerontik \& Geriatrik, Edisi 3. Jakarta : EGC.

Nursalam. (2013). Konsep Penerapan Metode Penelitian IImu Keperawatan. Jakarta : Salemba Medika.

Notoadmodjo, S. (2003). Pendidikan dan Perilaku Kesehatan. Jakarta : PT. Rineka Cipta

Notoadmodjo, S. (2007). Metode Penelitian Kesehatan. Jakarta : Rineka Cipta.

Notoatmodjo, S.( 2010 ). Promosi Kesehatan Teori dan Aplikasi. Jakarta : Rineka Cipta. Potter \& Perry. (2009). Buku Ajar Fundamental Keperawatan Konsep, Proses, dan Praktik, Edisi 3. Jakarta : EGC.

Potter et.al (2006). Buku Ajar Fundamental Keperawatan Konsep, Proses, dan Praktik, Edisi 2. Jakarta : EGC.

Ramlah. (2011). Hubungan Pelaksana Tugas Kesehatan Dan Dukungan Keluarga Dengan Pengabaian Lansia Di Wilayah Kerja Puskesmas Kassi-Kassi Makassar. Program Studi Magister IImu Keperawatan Peminatan Keperawatan Komunitas. Fakultas Ilmu Keperawatan Depok.

Rendy, M. (2013). Buku Saku : Keterampilan Dasar Keperawatan. Yogyakarta: Nuha Medika.

Rosy, R. (2014). Hubungan Prilaku Hygiene dan Kondisi Sanitasi Lingkungan dengan Kejadian Diare pada Lansi di UPTPUSKESMAS TALANGO.

Program Studi Ilmu Keperawatan. Universitas Wiraraja Sumenep.

Setiadi. (2013). Konsep \& Penulisan Riset Keperawatan. Yogyakarta : Graha IImu.

Setiadi. (2008). Konsep dan Proses Keperawatan Keluarga. Yogyakarta : Graha IImu.

Stanley and Beare. (2007). Buku Ajar Keperawatan Gerontik. Jakarta, EGC

Setyowati dan Murwani. (2007). Asuhan Keperawatan Keluarga, Konsep danAplikasi Kasus. Jogjakarta : Mitra Cendikia.

Tamher, S. Noorkasiani, (2009). Kesehatan Lanjut Usia dengan PendekatanAsuhan Keperawatan. Jakarta : Salemba Medika.

Wartonah, Tarwotoh. (2006). Kebutuhan Dasar Manusia dan Proses Keperawatan. Jakarta : Salemba Medika.

Zakariyah, A. (2009). Faktor-Faktor yang Berhubungan dengan Kemandirian pada Lanjut Usia di Panti Sosial Tresna Werdha (PSTW) Budi Mulia 04 Margaguna Jakarta Selatan Tahun 2009. Program Studi IImu Keperawatan Fakultas Kedokteran dan IImu Kesehatan : Universitas Islam Negeri Syarif Hidayatullah, Jakarta. 